\title{
LIMIT TERMS FOR SUMS OF DEPENDENT RANDOM VARIABLES
}

\author{
Submitted for publication to Naukova Dumka, Kiev, Ukraine \\ IGOR N. KOVALENKO \\ NIKOLAI N. LEONENKO \\ MIKHAII V. LEVASHOW \\ and \\ ALEXEI M. FAL \\ E-mail: kin@satnet.ms.kiev.ua
}

The monograph, consisting of two parts, is devoted to an exposition of methods for investigating dependent random variables. The first part deals with discrete parameter in which we investigated an asymptotic behavior of sums of dependent random variables. We have included generating functions, moments, projections, Steck, and Stein-Chen in our selection of methods. Each of the methods mentioned above has been assigned to a separate chapter for indepth coverage. Each chapter begins with an introduction to the method followed by proofs of some limit theorems. At the end of each chapter we summarize the results of that particular method.

In the second part, $\mathrm{N}$. Leonenko investigates asymptotic behavior of functionals for random fields. Leonenko also presents a systematic exposition of various notions and facts related to the definition and representation of random fields.

The new results include limit theorems for spherical means of local functionals of Gaussian random fields, a "total mass" of rejection above a moving level of a realization of Gaussian random field, and sojourn times in some sets of vector Gaussian random fields.

The last (tenth) chapter of the second part contains results on limit distributions of solutions to Burger's multi-dimensional equation with random initial conditions. Leonenko, primarily studied this topic and included his most recent results. 


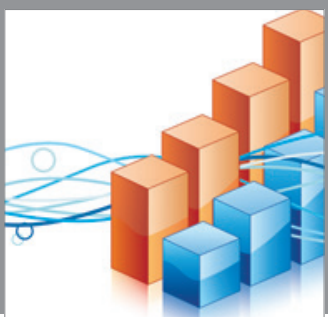

Advances in

Operations Research

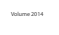

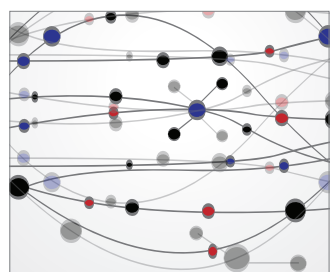

\section{The Scientific} World Journal
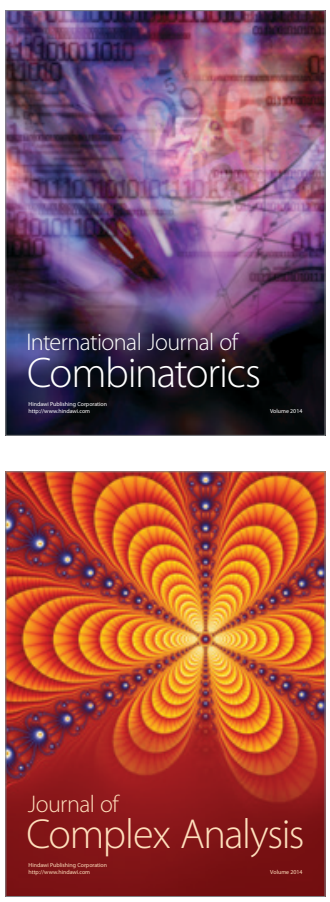

International Journal of

Mathematics and

Mathematical

Sciences
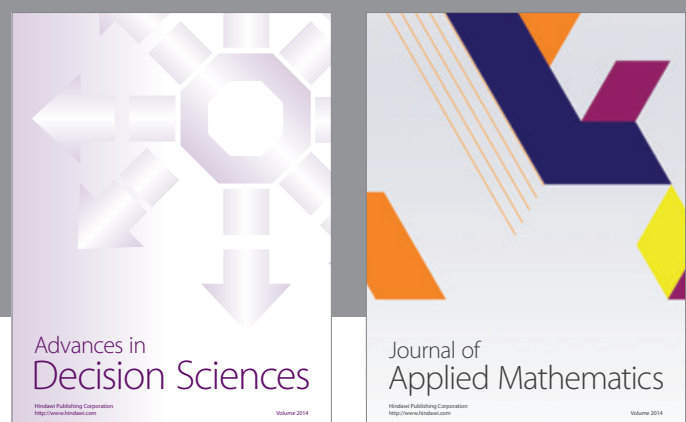

Journal of

Applied Mathematics
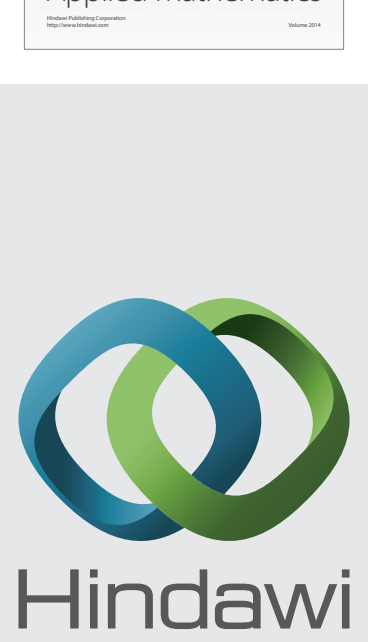

Submit your manuscripts at http://www.hindawi.com
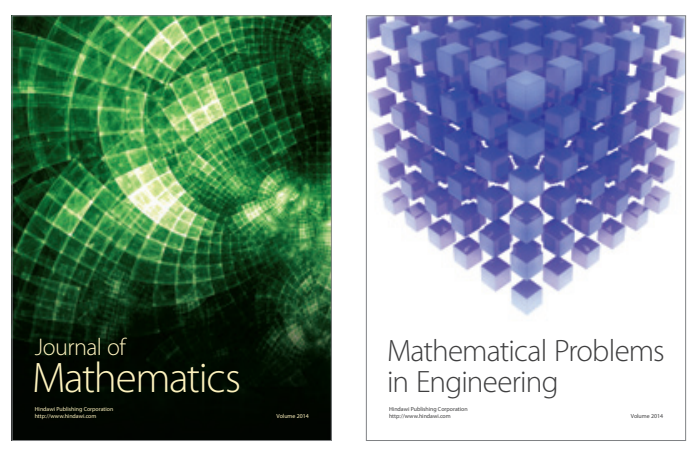

Mathematical Problems in Engineering
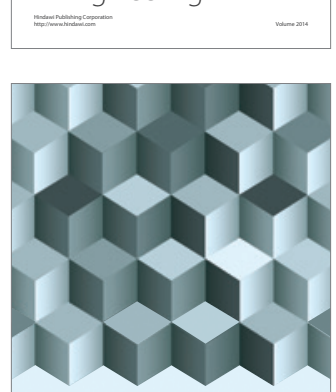

Journal of

Function Spaces
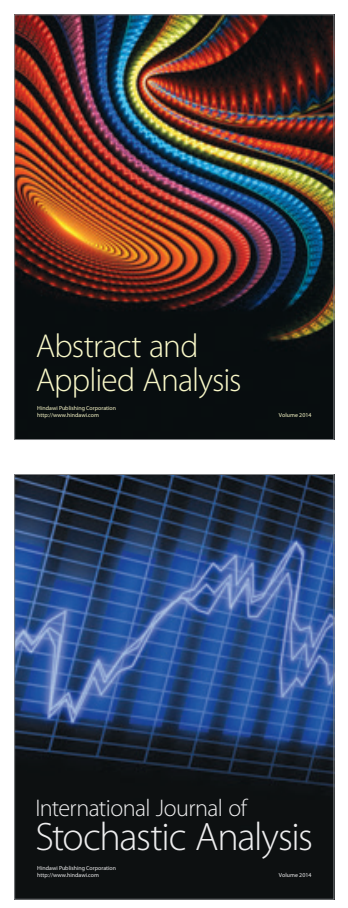

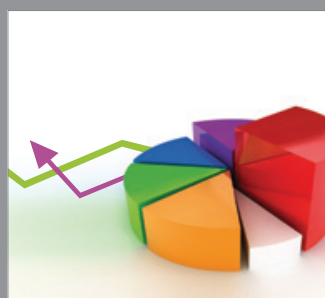

ournal of

Probability and Statistics

Promensencen
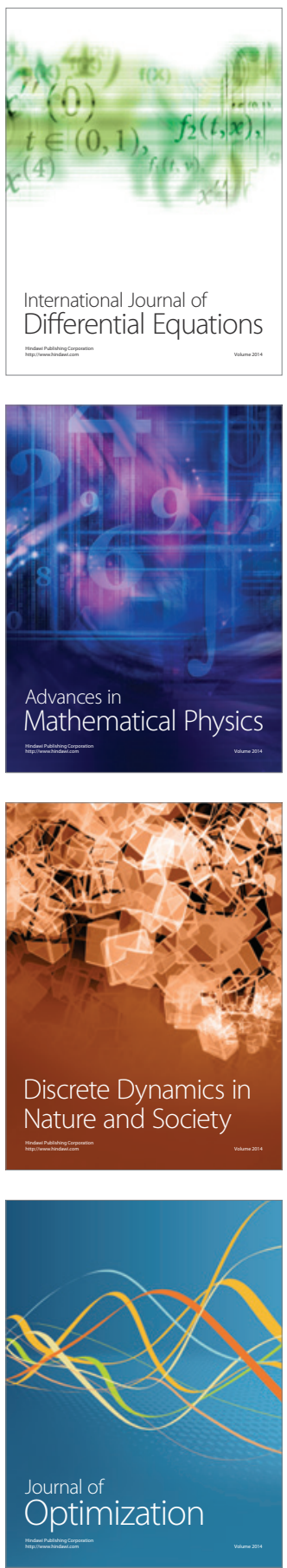